\title{
IR thermography used to detect thin defects versus numerical simulation results
}

\author{
by I. Simões*, N. Simões*, A. Tadeu* and J. Prata*
}

${ }^{*} \mathrm{CICC}$, Department of Civil Engineering, Faculty of Sciences and Technology, University of Coimbra, Rua Luís Reis Santos - Pólo II da Universidade, 3030-788 Coimbra, Portugal, \{mivsimoes, nasimoes, tadeu, jprata\}@itecons.uc.pt

\begin{abstract}
The work reports the experimental use of Infrared thermography (IRT) to detect embedded defects in mortar specimens. Surface temperature patterns are collected and compared with numerical solutions. The numerical formulations are based on frequency domain approaches using the coupling between the boundary element method and the method of fundamental solutions. Circular cylindrical ring and parallelepiped specimens incorporating thin defects are used. The heat diffusion within the test specimens is induced by line heat sources placed on their axes.
\end{abstract}

\section{Introduction}

The use of non-destructive techniques (NDTs) for the identification of defects is useful in several areas of knowledge such as engineering in civil, mechanical and aeronautical sciences, geophysical prospecting and medicine. In the case of civil engineering, NDTs are useful, for example, to detect internal voids, delaminations, and cracks in concrete structures such as bridge decks and highway pavements, as well as in walls and floors of buildings. The reliability of some structural and construction materials, composite structural systems and construction elements may be seriously affected by such internal defects. The early detection and characterization of cracks, voids and other defects is essential to preventing construction pathologies and material, or even structural, failure. There are several methods that can be use, including electromagnetic (nuclear, radar, thermography, magnetic, and electrical) and mechanical vibration (ultrasonic, acoustic, shock and vibration) techniques. It cannot be said that a particular method is better than any other because success depends on the type of defect that has to be characterized.

Infrared thermography (IRT) is a non-contact technique for the acquisition and analysis of thermal images using infrared radiation reader devices. All objects radiate energy that is proportional to the surface emissivity of the material and to the fourth power of the absolute surface temperature. Thus, higher surface temperatures allow more energy to be radiated. The hemispherical emissivity of a surface gives the ratio between the energy emitted by a surface of a particular material and the energy emitted by a perfect emitter (blackbody) at the same temperature and with an emissivity of one [[1], [2]]. Emissivity values may be between zero (perfect reflector, such as a mirror) and one (blackbody). Measuring temperatures on surfaces with low emissivity, such as well-polished metal surfaces and glass, is difficult because these surfaces reflect large amounts of energy emitted by nearby bodies. A review of emissivity measurement techniques and the importance of emissivity values on building diagnostics were presented by Avdelidis and Moropoulou [2]. They found that emissivity values of some materials are function of their temperature by applying two different approaches: one in accordance with ASTM standard E1933-97, and the other following an empirical procedure. They found that the emissivity values depend on the wavelength of the infrared thermographic region being analyzed. As Balaras and Argiriou state in the introduction of their work [1], temperature measurements using IRT are also dependent on other parameters such as ambient temperature, wind speed, distance to the target and air humidity.

The use of thermography for civil engineering applications has been proposed by several researchers in recent years to evaluate the thermal behavior of building/construction elements. Building diagnostics concerned with building heat loss analysis and detection of problems in mechanical and electrical installations [1], the characterization of envelope building solutions [3], the evaluation of heat transfer coefficients (U-Values) of building envelopes [4] and evaluation of thermal bridges in buildings [[3], [5]] are some examples of IRT applications.

In recent years, a body of work has been produced that confirms the potential of thermal imaging to evaluate and characterize defects [[6] - [10]] and evaluate material properties. Some of this research also involves the development of mathematical models for simulating heat transfer phenomena. Grinzato et al. [11] used quantitative transient IRT to evaluate hidden corrosion in metals, using halogen lamps to heat the external surface. They proposed a numerical model of heat transfer to solve the direct thermal problem and to detect thickness variations. Experimental temperature measurements were used to corroborate the numerical results.

Starnes [12] used thermography for the quality control of fiber-reinforced polymer composites. It was found that defects between the substrate and the fibers composite could be detected and characterized. This work also encompassed finite-element modeling and showed a good agreement between experimental thermal response parameters and those calculated with the numerical models [12].

Maierhofer et al. [13] detected different defects embedded in a concrete block heated by two radiators, using IRT. A finite difference model was developed to evaluate the influence of the inclusion cover, the void edge length, and the concrete thermal conductivity and density on the surface temperatures. An inverse form of this model was used to estimate the inclusion depth. 
The authors of the present paper have proposed several numerical formulations to simulate transient heat propagation using a frequency domain approach, particularly in the presence of stratified media with or without embedded inclusions [[14] - [17]]. Some of these numerical formulations have later been validated using experimental results ([18], [19]).

In this work, experimental and numerical simulations are performed to ascertain if the temperatures obtained on the test specimen's surface can be used to detect the presence of a thin defect. Two test specimens, made by coating a circular steel cylinder with mortar, were tested. The coating was applied so as to produce two different cross-sections: circular and quadrangular. These systems are heated using a line heat source placed on the axis of the steel core.

The test specimens are described next. Then the experimental set-up is defined, describing the test equipment used and the test procedure implemented. This is followed by the presentation of the surface temperature measurements obtained with an IRT system. Before the presentation of the numerical results there is a brief description of the numerical formulation.

\section{The specimens}

Two specimens are produced by coating a steel cylinder with mortar (see Figure 1). For one specimen the thickness of the mortar layer is constant, which produces a cylinder system (Figure 1a), while the second is formed as a quadrangular prism test specimen (see Figure 1b). In both test specimens the steel core has an external radius of $0.05 \mathrm{~m}$. The coating consists of a pre-dosed mortar mixture. The thickness of the mortar layer of the first specimen is a constant $0.028 \mathrm{~m}$, which defines a circular cylindrical system with an external diameter of $0.156 \mathrm{~m}$. The second specimen is a prism with a quadrangular cross section with edges measuring $0.156 \mathrm{~m}$. Both systems are $0.300 \mathrm{~m}$ high.

Internal defects were created between the mortar and the steel core by inserting a rubber thread when the specimen was being prepared. The defect is placed at the interface between the mortar and the steel core and is composed of a rubber strip approximately $30 \mathrm{~mm}$ thick, with a horizontal perimeter of $45 \mathrm{~mm}$. This defect extends along the full height of the specimens $\left(0.300 \mathrm{~m}\right.$ ) (see Figure 1). The rubber inclusion forms a circular concentric arc of $51.57^{\circ}($ $0.9 \mathrm{rad}$ ) with a radius of $51.5 \mathrm{~mm}$. Figures 1c) and d) show the transversal sections of each specimen, giving detais about the geometry and of the defect and test specimen.

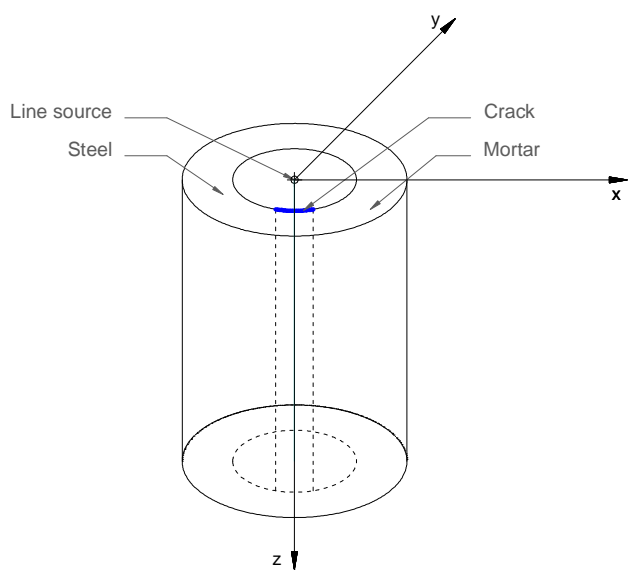

a)

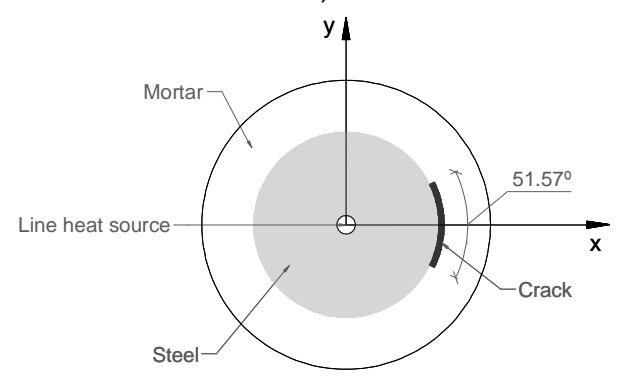

c)

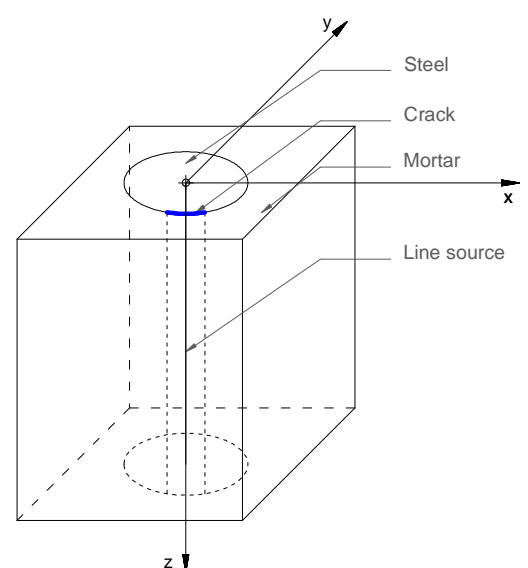

b)

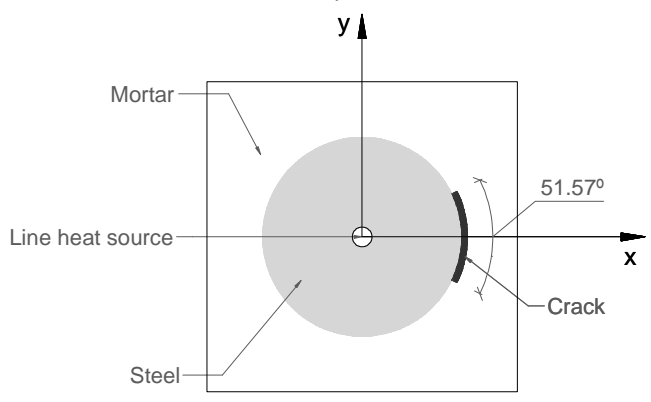

d)

Fig. 1. Geometry of test specimens: a) circular cylindrical system; b) rectangular prism system; c) cross-section of circular cylindrical system; d) cross-section of the quadrangular prism system.

The mortar was tested to determine its thermal conductivity, mass density and specific heat. The thermal conductivity was found by the guarded hot-plate method (ISO 8302:1991 [20]) using a Lambda-Mebtechnik GmbH 
Dresden apparatus, single-specimen Lambda-meter EP-500 model. The specific heat was obtained using a Netzsch apparatus, model DSC200F3, following the ratio method. The properties of the other used materials were obtained from technical documents.

Table 1 gives the averages of those properties for the three materials used in the experiments. the test specimens.

The thermal conductivity of the air was defined so as to simulate radiation and convection phenomena outside

Table 1. Materials' thermal properties

\begin{tabular}{|c|c|c|c|}
\hline Material & $\begin{array}{c}\text { Thermal conductivity, } \lambda \\
\left(\mathrm{W} \cdot \mathrm{m}^{-1} \cdot{ }^{\circ} \mathrm{C}^{-1}\right)\end{array}$ & $\begin{array}{c}\text { Mass density, } \rho \\
\left(\mathrm{kg} \cdot \mathrm{m}^{-3}\right)\end{array}$ & $\begin{array}{c}\text { Specific heat, } c \\
\left(\mathrm{~J} \cdot \mathrm{kg}^{-1} \cdot{ }^{\circ} \mathrm{C}^{-1}\right)\end{array}$ \\
\hline Steel & 72.0 & 7700.0 & 370.0 \\
\hline Pre-dosed mortar & 0.65 & 1400.0 & 840.0 \\
\hline Rubber & 0.03 & 80.0 & 1600.0 \\
\hline Air & 2.6 & 1.2928 & 1000.0 \\
\hline
\end{tabular}

\section{Experimental work}

The work was carried out using an IRT procedure to detect the defects buried in the mortar layer, by measuring the test specimens' surface temperatures generated by the heat diffusion phenomenon. In this section, the experimental testing procedure is described and the tests results are illustrated and commented upon.

\subsection{Experimental set-up and test procedure}

Tests were performed using an infrared (IR) video camera model A615 from Flir. IRControl software developed by Automation Technology was used for acquiring and processing the recorded images. All the tests were carried out in a controlled laboratory environment at a temperature of $(23 \pm 2)^{\circ} \mathrm{C}$ and relative of humidity of $(50 \pm 5) \%$. During the tests, the IR camera was positioned $0.75 \mathrm{~m}$ from the specimen, far enough to get a full view of the object. The test specimens were placed vertically and the camera was aligned perpendicular to the test specimen axis in a direction that intersected the central zone of the defect.

Power was supplied in the following sequence: the power of $5.0 \mathrm{~V}$ was not switched on for the first 3 minutes of temperature measurements; the power of the heat source was then turned on and kept constant for a certain period of time (11 minutes for the circular cylindrical test specimen and 20 minutes for the quadrangular prism system), at which instant it was turned off.

Before running the experimental tests the IR device was calibrated to provide a quantitative analysis of the thermal field. During the calibration procedure the emissivity of the superficial material and reflected temperature were evaluated.

\subsection{Circular cylindrical system results}

The IR thermograms were recorded over $50 \mathrm{~min}$. Figure 2 presents a set of snapshots of the surface temperature evolution to illustrate the result of the heat diffusion on the mortar surface as the time elapsed. A colour scale is used in the plots, with the red and purple shades corresponding respectively to higher $\left(28.0^{\circ} \mathrm{C}\right)$ and lower ( $23.0^{\circ} \mathrm{C}$ ) temperature values. Below each snapshot the temperature along a line, placed as indicated in the snapshot, illustrates the surface temperatures profile.

In the first plot, at $t=8 \mathrm{~min}$ (Figure 2a), after $5 \mathrm{~min}$ the heat source has started emitting energy, the temperature distribution does not show any evident difference. Along the line the temperature value is $23.7 \pm 0.2{ }^{\circ} \mathrm{C}$. 10 min after the heat source has been turned on (Figure $2 b$ ), the IR image presents a lower temperature value in the vicinity of the central area (where the defect has been placed). The temperature on the left surface appears to be slightly higher than on the right. The difference between the temperature on right side and that in the central zone is approximately $0.5^{\circ} \mathrm{C}$. This difference is more evident in Figure 2c), $21 \mathrm{~min}$ after the heat source was turned on, and $10 \mathrm{~min}$ after it was turned off. At this time, the temperature difference between the hottest (right surface) and coldest points, along the line shown in the snapshot, is $0.8^{\circ} \mathrm{C}$. As expected, as the heat propagation evolves the system tends to reach the equilibrium of energy. For this reason, $28 \mathrm{~min}$ after the heat source was turned off (Figure 2d), although, there is a variation of $0.4{ }^{\circ} \mathrm{C}$ along the line, the temperature distribution does not clearly show a marked difference. 


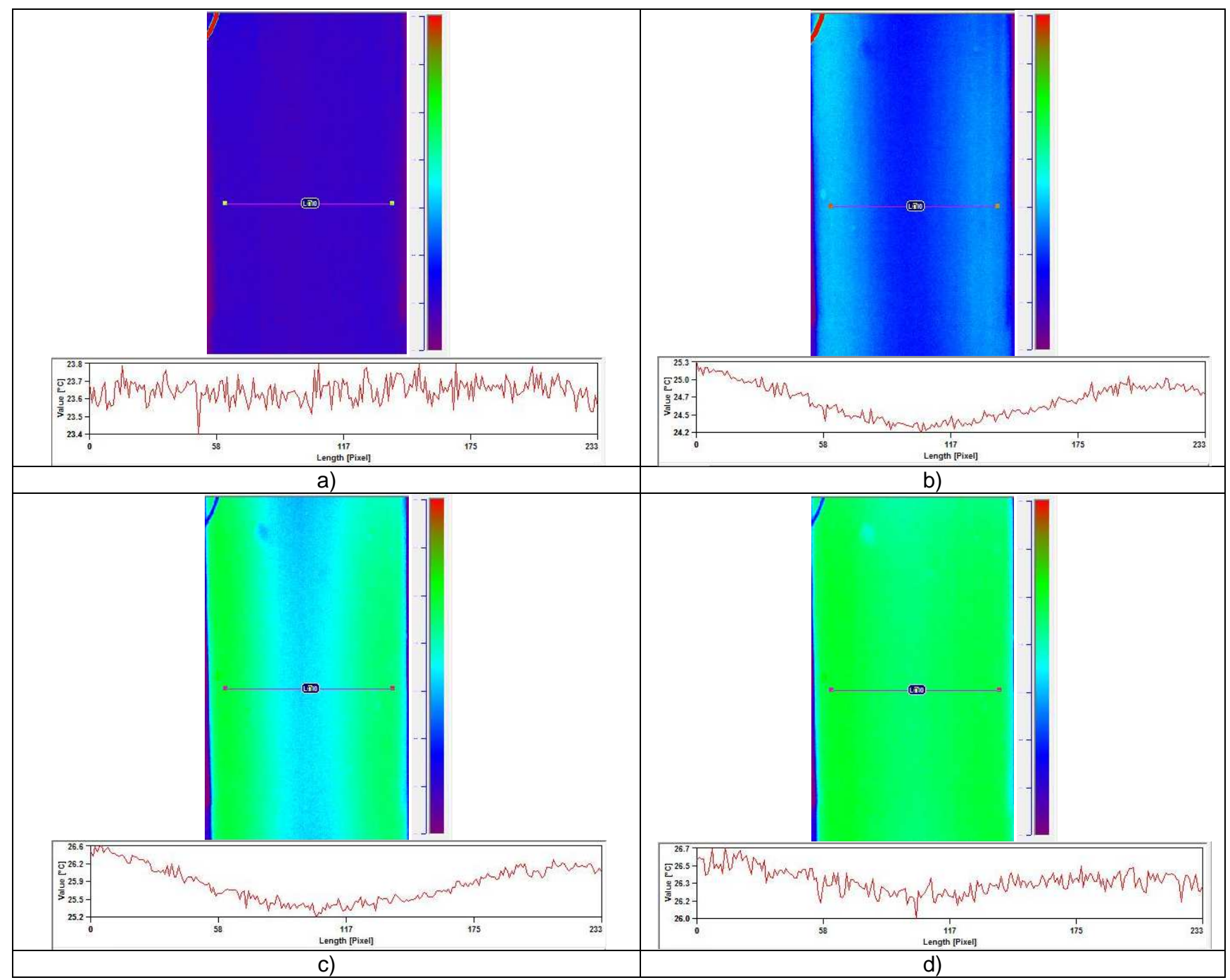

Fig. 2. Circular cylindrical system results at different time instants: a) $t=8 \mathrm{~min}-5 \mathrm{~min}$ after the heat source was turned on; b) $t=13 \mathrm{~min}-10 \mathrm{~min}$ after the heat source was turned on; c) $t=23 \mathrm{~min}-9 \mathrm{~min}$ after the heat source was turned off; d) $t=42 \mathrm{~min}-28 \mathrm{~min}$ after the heat source was turned off.

\subsection{Rectangular prism system results}

The procedure to identify the crack in the quadrangular prism system is similar to that described above. The only difference is the duration of the heating, which for this specimen was $20 \mathrm{~min}$.

As before, a set of snapshots, in Figure 3, illustrates how the surface temperatures of the test specimen changed as the time passed. The color scale used in the plots now ranges from $27.0^{\circ} \mathrm{C}$ (red shade) to $20.0^{\circ} \mathrm{C}$ (purple shade). As before, the snapshots include the profile of temperatures along a horizontal line.

In the first plot (Figure 3a), after $5 \mathrm{~min}$ the heat source has started emitting energy and the temperature distribution can be considered more or less constant $\left(20.4 \pm 0.3{ }^{\circ} \mathrm{C}\right)$, not showing any perturbation generated by the thin inclusion. In the second plot (Figure 3b), snapshot at instant $t=13 \mathrm{~min}$, the temperature field has changed. The temperature variation plotted allows the identification of three zones that register lower temperatures: in the vicinity of the edges of the test specimen (temperatures of about $20.6^{\circ} \mathrm{C}$ ) and in the central zone where the thin inclusion is embedded (temperatures of about $20.7^{\circ} \mathrm{C}$ ). This behavior is enhanced in the IR snapshot taken 13 min later (Figure 3c). $31 \mathrm{~min}$ after the heat source was turned off (Figure 2d), the influence of the thin inclusion on the surface temperature is weak. The edges of the test specimen still exhibit the lowest surface temperatures. 


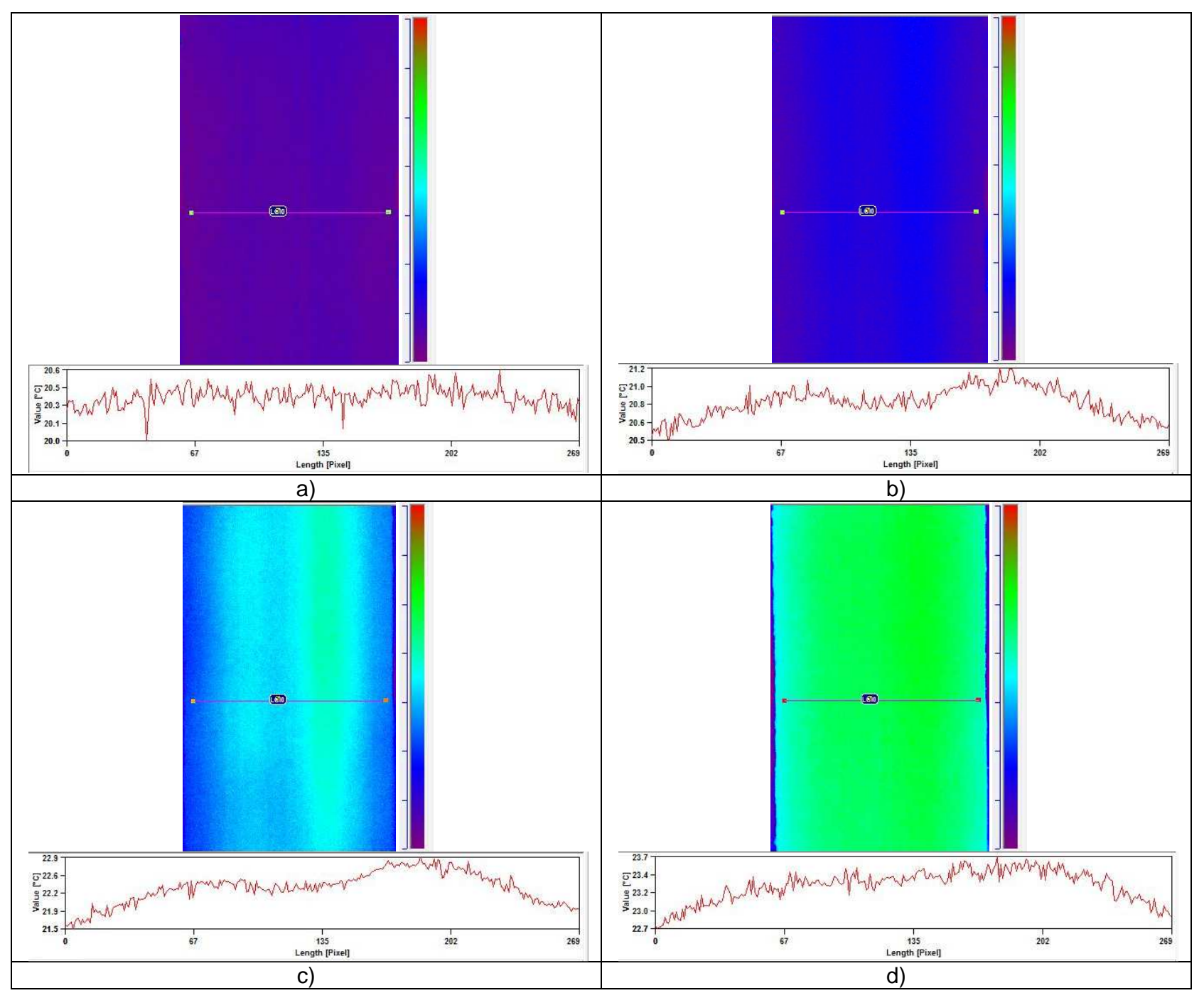

Fig. 3. Quadrangular prism system results at different time instants: a) $t=8 \mathrm{~min}-5 \mathrm{~min}$ after the heat source was turned on; b) $t=13 \mathrm{~min}$ - $10 \mathrm{~min}$ after the heat source was turned on; c) $t=26 \mathrm{~min}-3 \mathrm{~min}$ after the heat source was turned off; $d$ ) $t=54 \mathrm{~min}-31 \mathrm{~min}$ after the heat source was turned off.

\section{Numerical Formulation}

The numerical formulations are based on the coupling between the boundary element method (BEM)/the traction boundary element method (TBEM) and the method of fundamental solutions (MFS) [17] . The approach is implemented to solve 2D systems subjected to transient heat diffusion in presence of thin inclusions. The problem is formulated in the frequency domain. The thin defect is modeled using the TBEM and the BEM formulation while the MFS is used to model the steel and mortar interfaces. The computations are performed in the frequency domain. A numerical inverse fast Fourier transform is applied in the frequency domain to find the heat field in the time domain.

\subsection{Simulations}

The numerical simulation is implemented to evaluate the heat diffusion in the systems described above: a circular cylindrical ring and a quadrangular prism. The thermal properties of the materials are listed in Table 1 . These two systems are subjected to a harmonic line heat source placed in the steel medium at $(0.0,0.0) \mathrm{m}$. The source time dependence is assumed to be rectangular. It starts emitting energy at instant $t=3$ min and continues for 11 min (in circular cylindrical system) and $20 \mathrm{~min}$ (in quadrangular prism system), at constant power. The system is assumed to be initially at $24^{\circ} \mathrm{C}$. The power of the source is defined by means of the temperatures recorded experimentally by the thermocouple Tc2. The thermocouple Tc1 was used to verify the correct calibration of the source power. 
The computations are performed in the frequency domain for frequencies ranging from 0.0 to $0.01024 \mathrm{~Hz}$, with a frequency increment of $0.2 \times 10^{-4} \mathrm{~Hz}$, which determines a total time window for the analysis of $13.88 \mathrm{~h}$. This time window was considered enough to evaluate the heat transfer in study systems.

\subsubsection{Circular cylindrical system}

The circular cylindrical system results were computed at a grid of 2423 receivers placed along concentric circular curves from the system center to a radius of $0.128 \mathrm{~m}$. The numerical results are presented in two-dimensional views at different time instants (Figure 4), representing the temperature field throughout the full cross-section.

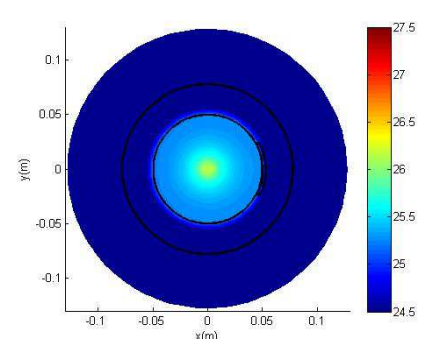

a)

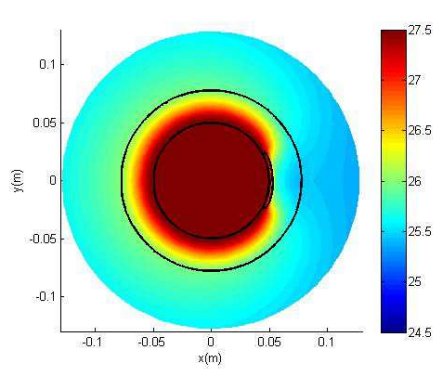

c)

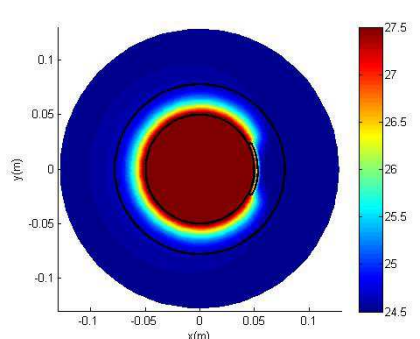

b)

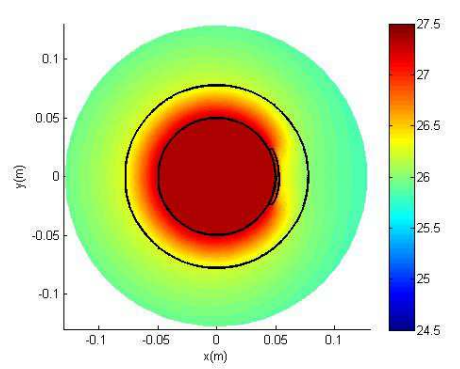

d)

Fig. 4. Circular cylindrical system results at different instants: a) $t=8 \mathrm{~min}-5 \mathrm{~min}$ after the heat source has been turned on; b) $t=13 \mathrm{~min}-10 \mathrm{~min}$ after the heat source has been turned on; c) $t=23 \mathrm{~min}$ - 9 min after the heat source has been turned off; d) $t=42 \mathrm{~min}-28 \mathrm{~min}$ after the heat source has been turned off.

In the first plot, at time $t=8 \mathrm{~min}$ (Figure 4a), the temperature distribution is starting to be affected by the presence of the thin inclusion, because the heat front has yet reached the defect. However, only a very small perturbation is observed. At $t=13 \mathrm{~min}$ (Figure $4 \mathrm{~b}$ ), the heat front component that passed through the thin inclusion has already reached the outer grid of receivers as it propagates away from the source position. The propagation of heat around the extremities of the inclusion is clearly visible. At time $t=23 \mathrm{~min}$, Figure $4 \mathrm{c}$, the source has already been turned off but the effect of the presence of the thin inclusion is more marked. In the last snapshot, taken at $t=42 \mathrm{~min}$ (Figure 4d), $28 \mathrm{~min}$ after the heat source has been turned off, it is interesting to note that the temperature is still rising in some regions of the domain.

To enable these results to be compared with those obtained experimentally with the IRT, the surface temperatures are plotted in the next figure for the same time instants. These curves are plotted using the $y$ coordinates of the receivers. As expected, all results are symmetric in relation to $y=0.0 \mathrm{~m}$, the center of the defect. As observed in the experimental results, the presence of the thin defect leads to lower temperature amplitudes on the model surface, close to where it is placed. The temperature along this line approaches those obtained experimentally. 


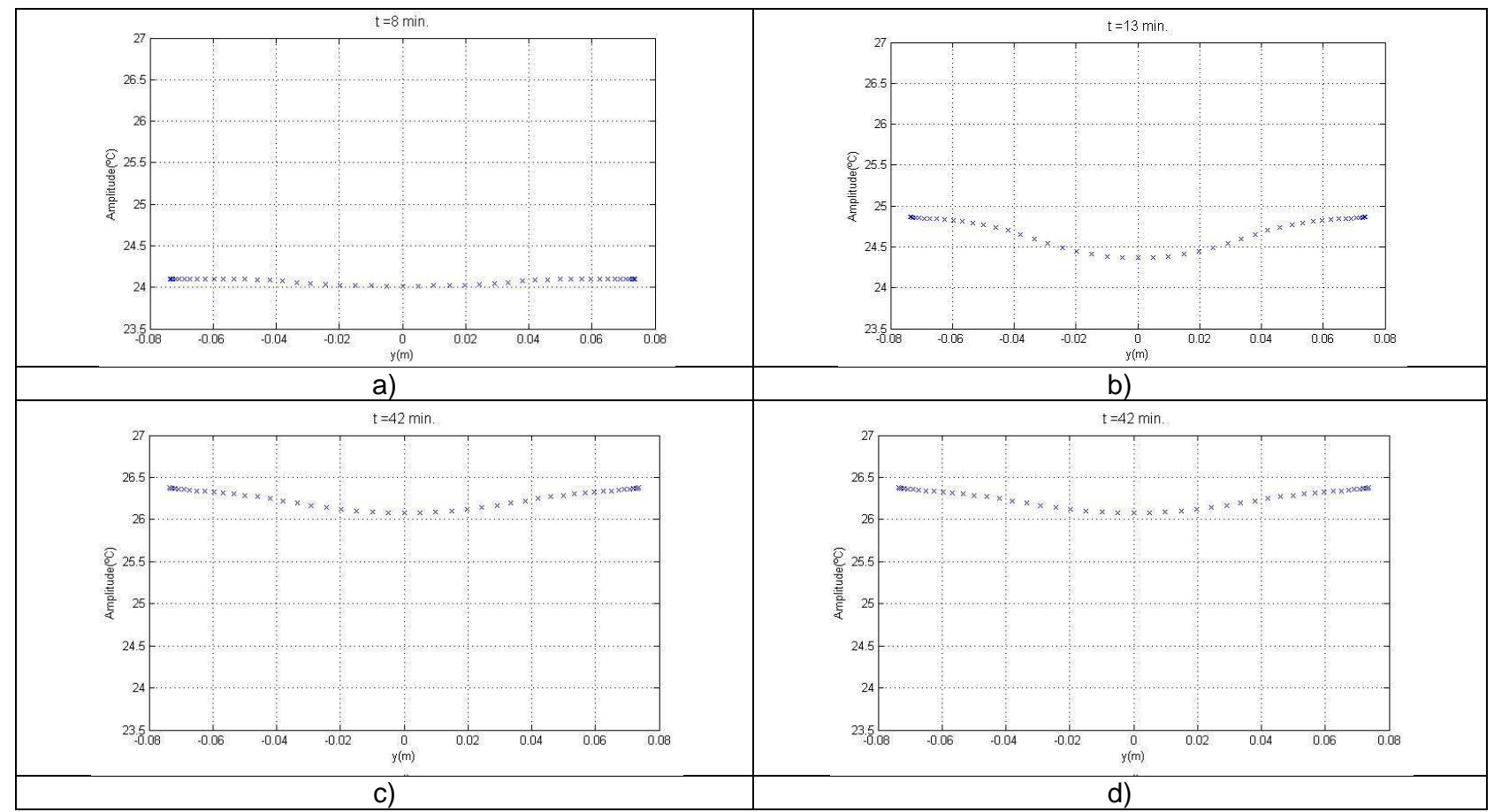

Fig. 5. Temperature profile on the exterior surface of the circular cylindrical system at different time instants registered by the numerical model: a) $t=8 \min$; b) $t=13 \min$; c) $t=23 \min$; d) $t=42 \min$.

\subsubsection{Rectangular prism system}

The quadrangular prism system results were computed at grid of 3720 receivers equally distributed within a square domain with edges of $0.3 \mathrm{~m}$. The numerical results are presented in snapshots taken at different time instants (Figure 6).

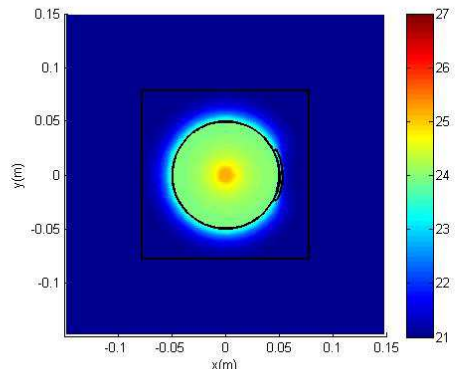

a)

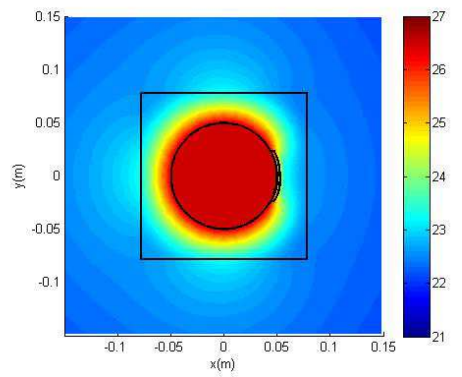

c)

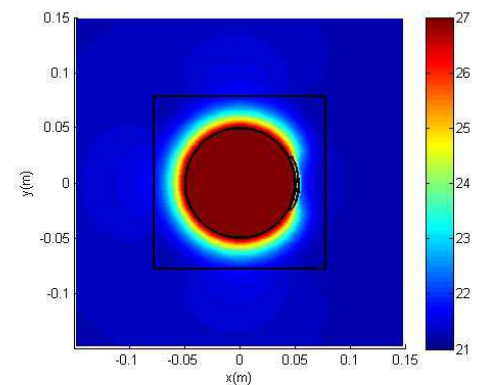

b)

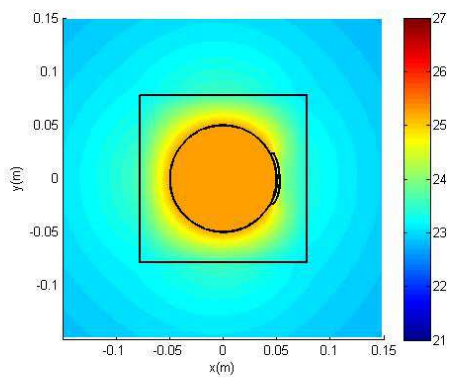

d)

Fig. 6. Quadrangular prism system results at different instants: a) $t=8 \mathrm{~min}-5 \mathrm{~min}$ after the heat source has been turned on; b) $t=13$ min - 10 min after the heat source has been turned on; c) $t=26$ min - 3 min after the heat source has been turned off; d) $t=54 \mathrm{~min}-31 \mathrm{~min}$ after the heat source has been turned off. 
At $t=8 \mathrm{~min}$ (Figure 6a), the temperature distribution is already affected by the presence of the thin inclusion embedded in the mortar layer. At this stage the perturbation caused by the thin defect does not yet affect the temperature registered at the exterior surface of the test specimen. At $t=13 \mathrm{~min}$ (Figure 6b), the heat front component that passed through the thin inclusion has already reached the outer medium (air), indicating the heat propagating away from the source position. The shape of the isothermal curves denotes not only the effect of the thin inclusion but also the type of geometry. Indeed, it is noticeable that the temperature values on the corners are lower than those registered at the neighboring points. This can be explained by the larger mass of mortar that needs to be heated at the quadrangular corners. The effect of the thin inclusion on the exterior surface temperature is now clearly visible. However, the temperature in the center of this surface is higher than those registered at the quadrangular corners. 3 min after the heat source has been turned off (Figure 6c), the surrounding air and mortar temperature is still rising, while the steel temperature starts decreasing. In the last snapshot, taken at $t=54 \mathrm{~min}$ (Figure $6 \mathrm{~d}$ ), $28 \mathrm{~min}$ after the heat source has been turned off, it is interesting to note that the temperature is still rising in some regions of the domain.

As before, to compare the numerical results with those obtained experimentally, the surface temperatures on the face of the quadrangular prism facing the thin defect are plotted for the same time instants analyzed. These curves are plotted using the $y$ coordinates of the receivers placed along a horizontal line on the test specimen surface. As found for the cylindrical test specimen, the results are symmetric in relation to $y=0.0 \mathrm{~m}$, the center of the defect. The lowest temperatures, as expected, are registered in the close vicinity of the test specimen corners. Figures $7 \mathrm{~b}$ and $7 \mathrm{c}$ bear out the same conclusions as drawn above: the central points register lower temperatures than those at the points in the immediate vicinity, but they are higher than those placed in the close vicinity of the test specimen. 31 min after the heat source has been turned off, the presence of the defect is not identifiable in the temperature profile on the external test specimen surface. The numerical conclusions are similar to those obtained experimentally.

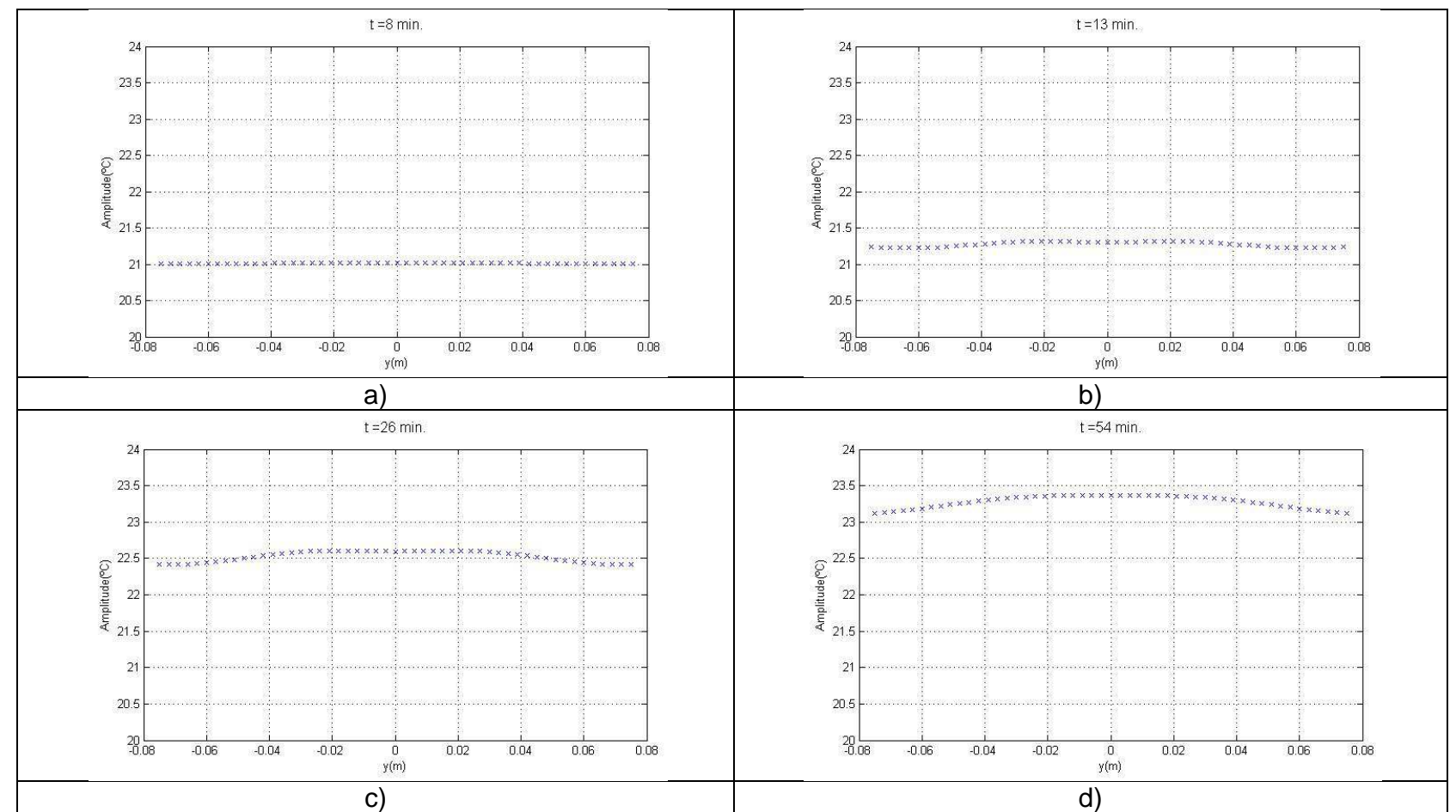

Fig. 7. Temperature profile on the exterior surface of the quadrangular prism obtained numerically at different time instants: a) $t=8 \mathrm{~min}$; b) $t=13 \mathrm{~min}$; c) $t=26 \mathrm{~min}$; d) $t=54 \mathrm{~min}$.

\section{Conclusions}

Thin heterogeneities embedded in a mortar layer coating a steel cylindrical circular core have been detected by analyzing the variation of surface temperatures on test specimens, using infrared thermography. Two different external surfaces were tested: a cylindrical circular surface built when the thickness of the applied mortar layer is constant and a plane surface defined by embedding the steel core in a quadrangular prism of mortar. A line heat source placed at the center of the system was used to create heat diffusion. Analysis of the results made it possible to verify that when the mortar layer has a constant thickness, as in the cylindrical circular system, the presence of the thin inclusion leads to larger temperature differences at the surface, which makes its detection easier.

The diffusion phenomenon was also simulated numerically and the surface temperatures computed. The numerical simulations used a coupling formulation between the boundary element method and the method of fundamental 
solutions. This approach is formulated in the frequency domain and time solutions are obtained by means of inverse Fourier transforms. The comparison between numerical and experimental results showed that the numerical model can adequately simulate the heat diffusion phenomena. Thus, the surface temperature patterns defined by numerical simulations can be used to define in which conditions IRT can be successful in detecting the presence of embedded heterogeneities.

\section{ACKNOWLEDGMENTS}

The research work presented herein was supported by FEDER funds through the Operational Programme for Competitiveness Factors - COMPETE and by national funds through the FCT - Portuguese Foundation for Science and Technology), under research project PTDC/ECM/114189/2009, and doctoral grant SFRH/BD/48138/2008.

\section{REFERENCES}

[1] Balaras, C.A., Argiriou, A.A., "Infrared thermography for buildings diagnostics". Energy and buildings, vol. 34, pp. 171-183, 2002.

[2] Avdelidis, N.P., Moropoulou, A., "Emissivity considerations in building thermography". Energy and Buildings, vol. 35, pp. 663-667, 2003.

[3] Zalewski L., Lassue S., Rousse D., Boukhalfa K., "Experimental and numerical characterization of thermal bridges in prefabricated building walls". Energy Conversion and Management, vol. 51, pp. 2869-2877, 2010.

[4] Fokaides, P.A., Kalogirou, S.A., "Application of infrared thermography for the determination of the overall heat transfer coefficient (U-Value) in building envelopes". Applied Energy, vol. 88(12), pp. 4358-4365, 2011.

[5] Asdrubali, F., Baldinelli G., Bianchi F., "A quantitative methodology to evaluated thermal bridges in buildings". Applied Energy, 2012 (article in press).

[6] Vavilov, V., Maldaguq, X., Dufort, B., Robitaille, F., Picard, J. "Thermal Nondestructive Testing of Carbon Epoxy Composites: Detailed Analysis and Data Processing.", NDT \& E International, vol. 26, n. ㅇ 2, pp. 85-95, 1993.

[7] Connolly, M.P., "A Review of Factors Influencing Defect Detection in Infrared Thermography: Application to Coated Materials". Journal of Nondestructive Evaluation, vol. 10, n.ำ 3, pp. 89-96, 1991.

[8] Connolly, M.P., "The Measurement of Porosity in Composite Materials Using Infrared Thermography". Journal of Reinforced Plastics and Composites, vol. 11, n.ำ 2, pp 1367-1375, 1992.

[9] Cielo, P., Maldague, X., Déom, A.A., Lewark, R., "Thermography Nondestructive Evaluation of Industrial Materials and Structures". Materials Evaluation, vol. 45, n.ำ 6, pp. 452-460, 1987.

[10] Dattoma, V., Marcuccio, R., Pappalettere, C., Smith, G.M., "Thermographic Investigation of Sandwich Structure Made of Composite Material", NDT \& E International, vol. 34, pp. 515-520, 2001.

[11] Grinzato, E., Vavilov, V., "Corrosion evaluation by thermal image processing and 3D modeling", Revue Générale de Thermique", vol. 37(8), pp. 669-679, 1998.

[12] Starnes M.A., Carino, N.J., Kausel E.A., "Preliminary thermography studies for quality control f concrete structures strengthened with fiber-reinforced polymer composites", Journal of materials in Civil Engineering, vol. 15(3), pp. 266-273, 2003.

[13] Maierhofer, Ch., Brink, A., Rolling, M., Wiggenhauser, H., "Quantitative impulse-thermography as nondestructive testing method in civil engineering - Experimental results and numerical simulation", Construction and Building Materials, vol. 19, pp 731-737, 2005.

[14] Tadeu, A., António, J., Simões, N., "2.5D Green's Functions in the Frequency Domain for Heat Conduction Problems in Unbounded, Half-space, Slab and Layered Media”, CMES - Computer Modeling in Engineering \& Sciences, vol. 6(1), pp 43-58, 2004.

[15] Tadeu, A., António, J., Godinho, L., Simões, N., "Transient heat conduction in a solid layer containing inclusions via the Boundary Element Method", Computational Mechanics Journal, vol.34, pp 99-110, 2004.

[16] Simões, N., Tadeu, A., "Transient conduction and convection heat transfer across a multi-layer floor subjected to multiple heat sources". Building and Environment, 41(10), pp. 1299-1310, 2006.

[17] Tadeu A., Simões N., Simões I., "Coupling BEM/TBEM and MFS for the simulation of transient conduction heat transfer", International Journal for Numerical Methods in Engineering, vol. 84, pp. 179-213, 2010.

[18] Simões, N., Simões, I., Tadeu, A., "3D transient heat conduction in multilayer systems - Experimental validation of semi-analytical solution", International Journal of thermal Sciences, vol. 57, pp. 192-203, 2012.

[19] Simões, I., Simões, N., Tadeu, A., Reis, M.M., Vasconcellos, C.A.B., Mansur, W.J., "Experimental validation of a frequency domain BEM model to study $2 \mathrm{D}$ and $2.5 \mathrm{D}$ heat transfer by conduction" (accepted for publication April 2012)

[20] International Organization for Standardization, ISO 8302: Thermal insulation - Determination of steady-state thermal resistance and related properties - Guarded hot plate apparatus (1991). 